\title{
SOLAR ENERGY FOR SEAWATER DESALINATION: REVIEW OF ECONOMICS
}

\author{
A. E. Kabeel, Emad M. S. El-Said \\ Mechanical Power Engineering Department, Faculty of Engineering, Tanta University, Tanta, \\ Egypt
}

\begin{abstract}
Major desalination processes consume a large amount of energy derived from oil and natural gas as heat and electricity, while emitting harmful $\mathrm{CO}_{2}$. Solar desalination has emerged as a promising solar energy-powered technology for producing fresh water. This paper will provide an overview of the economics of solar desalination with an emphasis on the Saudi fact in order to estimate the economic benefits of it in comparison with other desalination systems.
\end{abstract}

Keywords: Solar desalination; Water production cost; Energy cost; Economics

\section{Introduction}

Desalination has been identified for many years as an important source to provide the need of fresh water, and used in several techniques, including multi-stage flash, reverse osmosis, electrodialysis, but these techniques need to manage large amounts of energy that can be provided from sources of fossil fuels or electricity, thus it is expensive and contributes to the polluted environment to the fact that these sources are non-renewable and difficult to obtain, sometimes also considered. The possibilities of water desalination using nuclear energy and that with what distinguish him from productivity and cheap in cost, but it needs high technology and difficult to collect and dispose of nuclear waste resulting there from as well as problems of safety related, and here came the idea of the exploitation of solar energy in water desalination has been done by photovoltaic cells that convert solar energy directly into energy Power operates desalination plants, or by taking advantage of the sun's heat to heat water, vaporized and condensed to obtain desalinated water or multi-stage distillation using solar collectors.

The lack of fresh water resources in Saudi Arabia is becoming an increasing problem, as it is elsewhere around the world. Local officials there estimate that the country's more than 28 desalination plants provide between $50-70 \%$ of the country's drinking water, a process that requires oil to run the huge equipment needed to extract salt and other minerals [1].

Seawater desalination in the Arabian Gulf and the Red Sea is the reliable source of water supply to the population of Kuwait, Saudi Arabia, Bahrain, Qatar, and the United Arab Emirates. In these countries with abundant solar energy, solar desalination could be one of the most successful applications of solar energy. A number of factors determine the capital and operating costs for desalination: capacity and type of facility, location, feed water, labor, energy, financing and concentrate disposal. The purchase or production of renewable energy to power desalination plants naturally adds to the capital and/or operating costs of desalination. One study argues that water desalination which depends on traditional energy sources may be a solution for some water-stress regions, but not for places that are poor, deep in the interior of a continent, or at high elevation. Unfortunately, that includes some of the places with biggest water problems. and Indeed, one needs to lift the water by $2000 \mathrm{~m}$, or transport it over more than $1600 \mathrm{~km}$ to get transport costs equal to the desalination costs. In Saudi Arabia, after being desalinated at Jubail, , water is pumped 200 miles 
(320 km) inland through a pipeline to the capital city of Riyadh. So, for cities on the coast, desalination is being increasingly viewed as an untapped and unlimited water source [2].

Thus, it may be more economical to transport fresh water from somewhere else than to desalinate it. In places far from the sea, like New Delhi, or in high places, like Mexico City, high transport costs would add to the high desalination costs. Desalinated water is also expensive in places that are both somewhat far from the sea and somewhat high, such as Riyadh and Harare. In many places, the dominant cost is desalination, not transport; the process would therefore be relatively less expensive in places like Beijing, Bangkok, Zaragoza, Phoenix, and, of course, coastal cities like Jeddah [3] .

The solar plants in Saudi Arabia expected to produce water and electricity at a cost ranging between 0.27 to $0.4 \$$ instead of the current cost of 0.67 to $1.5 \$$ per cubic meter and the cost of electricity production using the solar cells of that have been developed of less than $0.08 \$$ per $\mathrm{kW} / \mathrm{hr}$ [1].

\section{Why solar energy for Seawater Desalination?}

Apart from the referred reasonable arguments for the use of renewable energy sources towards the emerging and stressing energy problems, there are a number of reasons related to the more specific issue, the one of the suitability of renewable energy sources for seawater desalination:

- The desalination plants which power from renewable sources, thereby eliminating harmful greenhouse gas emissions to the environment

- Arid regions are often remote, coastal areas or little islands where renewable energy sources are available and conventional energy supply is not always possible or at least easy to implement. In these cases renewable energy sources represent the best energy supply option for autonomous desalination systems.

- Climatic reasons lead to remarkable agreement on a time-basis, between the availability of renewable energy sources, especially when referring to solar energy, and the intensive demand of water. Furthermore, often freshwater demand increases due to tourism, which is normally concentrated at times when the renewable energy availability is high.

- Both renewable energy systems and desalination refer to self-sufficiency and local support. The operation and maintenance of related systems in remote areas are often easier than conventional energy ones. Furthermore, the implementation of renewable energy sources-driven desalination systems enforces sustainable socioeconomic development by using local resources.

- Renewable supply. This has to be seen energies allow diversification of energy resources and help to avoid external dependence on energy through the prospect of the least developed countries, where major water shortage problems exist, considering as well the fact that seawater desalination processes are highly energy-consuming methods.

- Site requirements and resources availability has a good match with need for desalination.

\section{Matching Solar Energy with Desalination Units}

Solar energy and desalination plants are two different technologies, which can be combined in various ways. The interface between the solar energy system and the desalination system is met at the place/subsystem where the energy generated by the solar system is promoted to the desalination plant. This energy can be in different forms such as thermal energy, electricity or Photovoltaic. Fig. 1 shows the possible combinations. Solar energy-driven desalination systems fall into two main categories: thermal processes and photovoltaic processes. As regards the energy source, a desalination plant powered by solar energy is likely to be a stand-alone system at a location which has no electricity grid. In order to ensure continuous or semi-continuous operation independent of weather conditions, stand-alone systems usually include a storage device. In recent years, due to 
intensive R\&D efforts and to operation experience gained, advances in conventional desalination plants, steam or electrically driven, refer to a significant efficiency increase and reduction of cost.

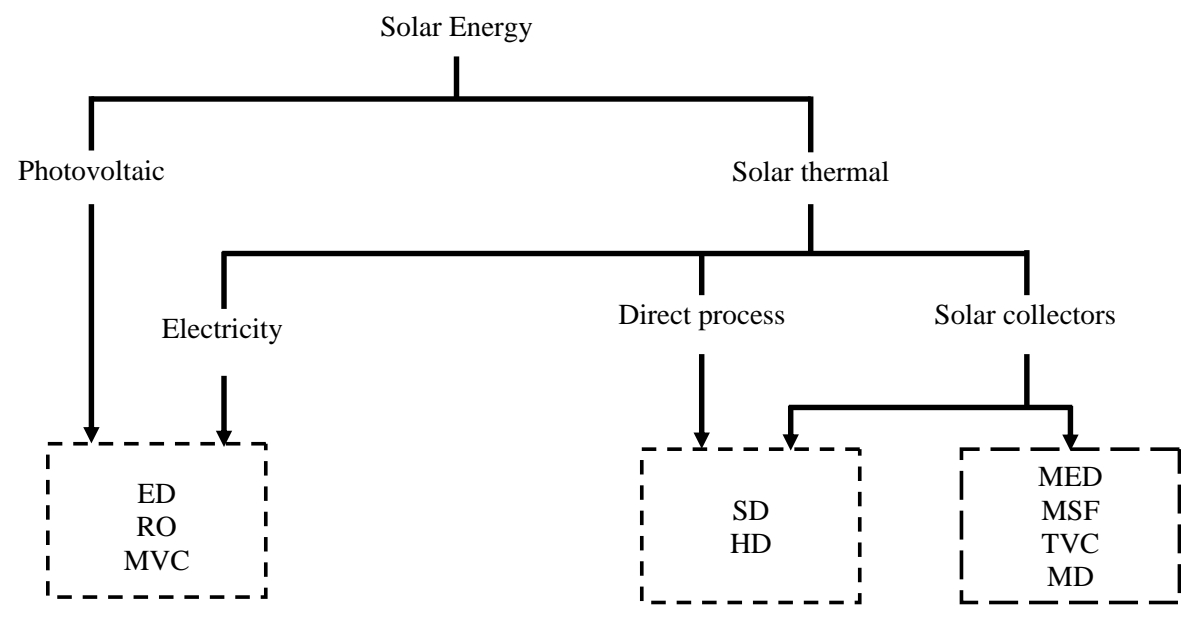

Fig. 1.Possible technological combinations of the solar energy and desalination methods.

On the otherdesalination systems is quite different. At present time, these systems evolve through the R\&D stage, or they are implemented as pilot plant size applications, presenting, in general, capacities from a few $\mathrm{m}^{3}$ up to $100 \mathrm{~m}^{3}$. There have also been some demonstration plants of medium size, mainly solar-powered, but a minority of those has presented successful operation characteristics [4,5]. Not all the combinations of solar energy-driven desalination systems are considered to be suitable for practical applications; many of these possible combinations may not be viable under certain circumstances. The optimum or just simple specific technology combination must be studied in connection to various local parameters as geographical conditions, topography of the site, capacity and type of energy available in low cost, availability of local infrastructures (including electricity grid), plant size and feed water salinity. General selection criteria may include robustness, simplicity of operation, low maintenance, compact size, easy transportation to site, simple pre-treatment and intake system to ensure proper operation and endurance of a plant at the often difficult conditions of the remote areas. Table 1 gives an overview of recommended combinations depending on several input parameters, noting though that other, additional combinations are also possible [4].

Table 1: Recommended solar energy-desalination combinations.

\begin{tabular}{|c|c|c|c|c|c|c|}
\hline \multirow[b]{2}{*}{$\begin{array}{c}\text { Feed } \\
\text { water } \\
\text { avilable }\end{array}$} & \multirow[b]{2}{*}{$\begin{array}{l}\text { Product } \\
\text { water }\end{array}$} & \multirow[b]{2}{*}{$\begin{array}{l}\text { Energy } \\
\text { source }\end{array}$} & \multicolumn{3}{|c|}{ System size } & \multirow[b]{2}{*}{$\begin{array}{c}\text { Suitable solar } \\
\text { energy-desalination } \\
\text { combination }\end{array}$} \\
\hline & & & $\begin{array}{c}\text { Small, } \\
1-50 \\
\mathrm{~m}^{3} / \mathrm{d}\end{array}$ & $\begin{array}{c}\text { Small, } \\
50-250 \\
\mathrm{~m}^{3} / \mathrm{d}\end{array}$ & $\begin{array}{c}\text { Large, } \\
>250 \\
\mathrm{~m}^{3} / \mathrm{d}\end{array}$ & \\
\hline \multirow{3}{*}{$\begin{array}{l}\text { Brackish } \\
\text { water }\end{array}$} & Desalinate & Solar & $*$ & & & Solar distillation \\
\hline & Potable & Solar & * & & & PV-RO \\
\hline & Potable & Solar & * & & & PV-ED \\
\hline \multirow{5}{*}{ Sea water } & Desalinate & Solar & * & & & Solar distillation \\
\hline & Desalinate & Solar & & $*$ & $*$ & Solar thermal-MED \\
\hline & Desalinate & Solar & & & * & Solar thermal-MSF \\
\hline & Potable & Solar & * & & & PV-RO \\
\hline & Potable & Solar & * & & & PV-ED \\
\hline
\end{tabular}




\section{Solar Energy in Saudi Arabia}

Although the sun light captured by earth excessively meets of world's need, we can use a few amount of this source. Solar energy supported desalination is one of the method developed for desalination. The amount of solar energy reflected by the Earth, as shown by the diagram in Fig.2, on average around $70 \%$ of solar energy is absorbed, and 30\% reflected. $>80 \%$ of solar energy is reflected by fresh snow while $<10 \%$ is reflected by dense forest areas [6].

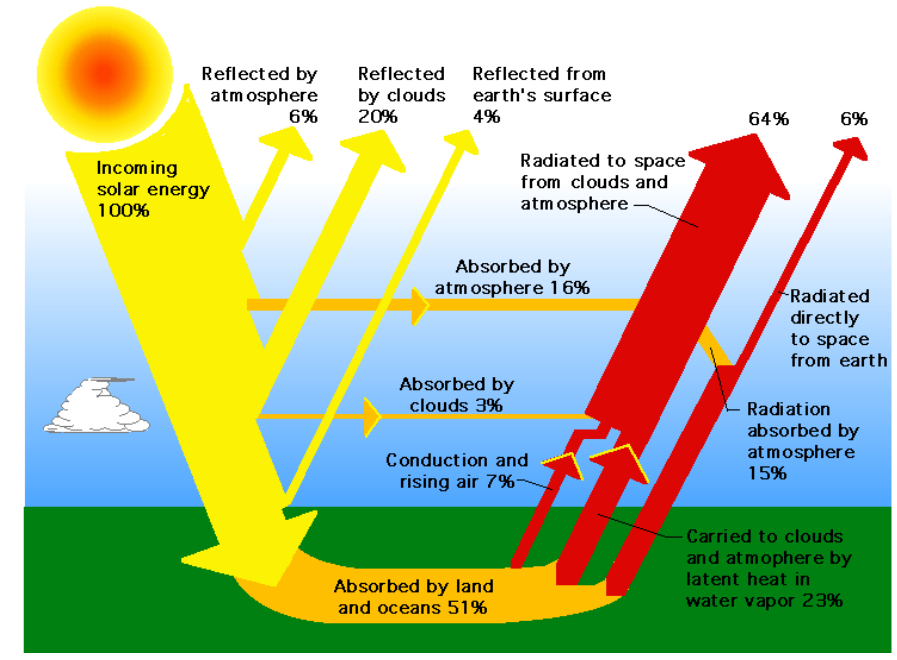

Fig. 2.Earth's solar energy budget.

Fig. 3. Shows regions of high insolation where solar energy conversion systems will produce the maximum amount of energy from a specific collector field size. However, solar energy is available over the entire globe, and only the size of the collector field needs to be increased to provide the same amount of heat or electricity as in the shaded areas. It is the primary task of the solar energy system designer to determine the amount, quality and timing of the solar energy available at the site selected for installing a solar energy conversion system.

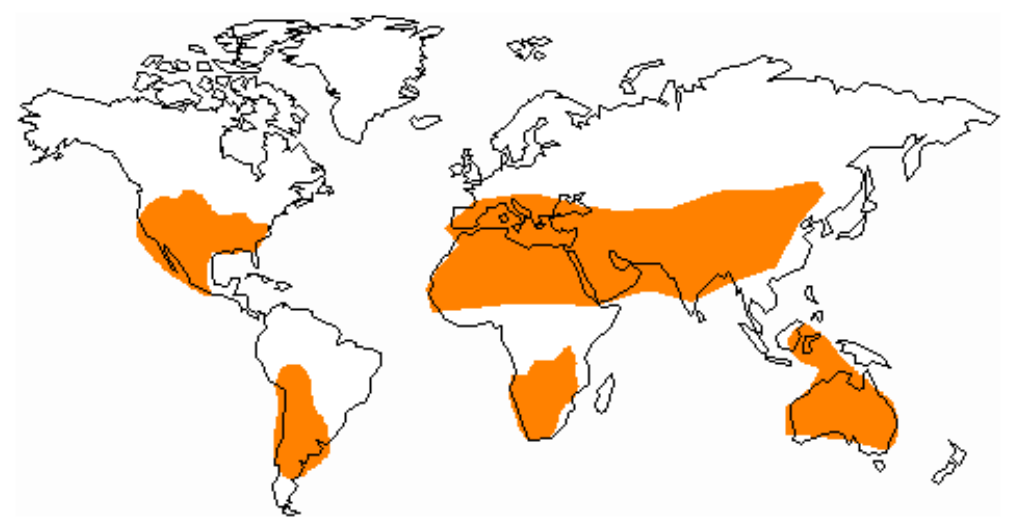

Fig. 3 Areas of the world with high insolation.

Saudi Arabia has build its richness primarily on exporting oil but oil won't last for eternity, and this is one of the reasons why Saudi Arabia has started introducing solar energy into the kingdom. Saudi Arabia has begun building the first solar-powered water desalination plant as the first step that should give significant boost to the development of solar energy sector in the country. Saudi Arabia has abundant sunshine throughout the whole year, and according to the official data, the Sun in Saudi Arabia emits about 7,000 watts of energy per square meter over an average of 12 hours [7]. Since, 
the economical production of solar electricity requires radiation of $1700 \mathrm{kWh} / \mathrm{m}^{2} /$ year or $4-5$ $\mathrm{kW} / \mathrm{hr} / \mathrm{m}^{2} /$ day. All Arab countries are among those who intercept more than the amount of 1700 $\mathrm{kWh} / \mathrm{m}^{2} /$ year [8]. This means that the potential of solar energy in Saudi Arabia is really huge, and Saudi Arabia definitely has enough money to start financing solar energy projects.

\section{Socio-Economic Impacts}

The cost of heat from concentrating solar collector fields is at present equivalent to heat from fuel oil at $50 \$ /$ barrel, heading for $35 \$ /$ barrel around 2010 and $20 \$ /$ barrel by 2020 . In the long-term a cost of $15 \$ /$ barrel will be achievable for solar "fuel" while fossil fuel is not expected to ever return to such low levels equivalent to those in the mid 1990ies. This means that heat from concentrating solar collector fields will become one of the least cost options for energy in MENA, if not the cheapest at all. Fig. 4 and Fig.5 show that CSP plants providing power and desalted water can be operated economically with attractive interest rates if reasonable, unsubsidized prices are paid either for electricity or water. This must be seen in the context of present power and water utilities in MENA, that often show a zero or negative rate of return of investment, thus highly subsidizing power and water. While it is clear that the threatening MENA water crisis cannot be solved by conventional desalination, it can indeed be solved by solar powered desalination combined with efficient use of water reserves and re-use of wastewater. Building water supply on limited, fossil energy resources with unknown cost perspectives would be very risky, while building a reasonable share of water supply on renewable resources that become cheaper with time would be rather reasonable. CSP-desalination can also help to reduce the subsidiary load of most MENA governments from the power and water sectors and thus liberate public funds that are badly needed for innovation and development. After comparing the expected cost of solar powered seawater desalination, the cost of measures to increase the efficiency of water use and economic losses induced by the over-use of groundwater, we found that the unsustainable use of groundwater is not only a threat to the environment, but also to the national economies that suffer under such schemes, with losses of national income by a reduced gross domestic product amounting to billions every year. Sound investments and favourable economic frame conditions are now required to start market introduction and massive expansion of CSP for power and desalination in the MENA region. A population doubling until 2050 will not only require more energy and water, but also more space for living. CSP opens the long-term option to gain arable land from the MENA deserts for rural and urban development for the generations to come. Instead of increasingly fighting for limited resources, MENA has the opportunity to change to a cooperative exploitation of renewable ones [9].

\section{Long-Term Markets for Seawater Desalination until 2050 in Saudi Arabia}

In Saudi Arabia, the non- sustainable over-use of groundwater makes up for the largest portion of freshwater supply, with a maximum of $19 \mathrm{Bm}^{3} / \mathrm{y}$ (Fig. 6 and Table 2). Today's total demand of about $26 \mathrm{Bm}^{3} / \mathrm{y}$ will at least $150 \%$ until 2050 , which must be compared to a natural exploitable water resource of only $2.4 \mathrm{Bm}^{3} / \mathrm{y}$. Until 2020, fossil-fuel-powered desalination will become the second most important source of freshwater, which is also a source that is not considered sustainable in economical and environmental terms. 


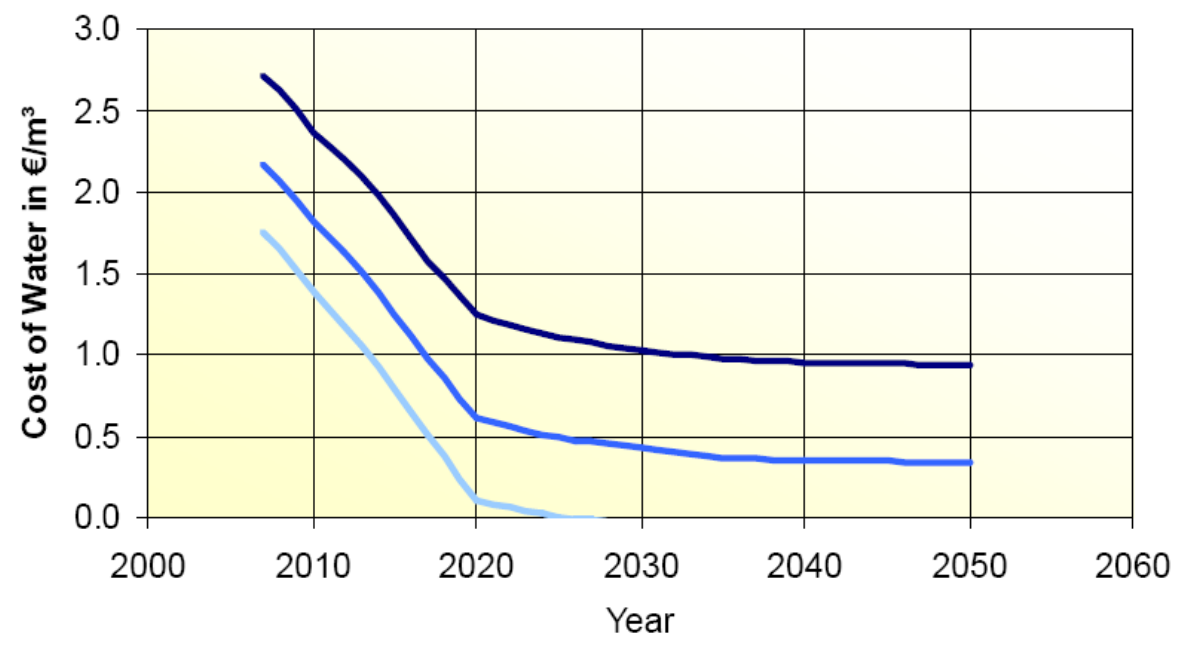

$0 \%$ Interest Rate $-5 \%$ Interest Rate $-10 \%$ Interest Rate

Fig.4. Cost of water from CSP/MED plants for different interest rates.

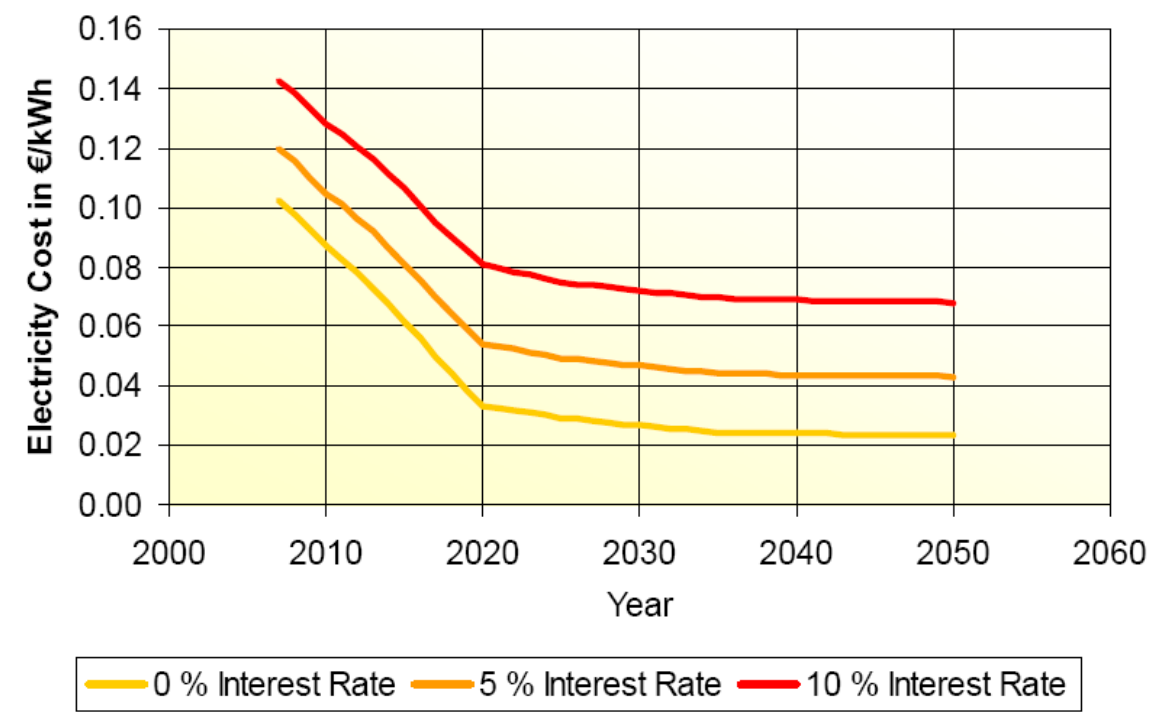

Fig.5. Cost of electricity from CSP/MED plants for different interest rates.

This makes the Saudi Arabian in a critical, not because of its absolute deficits, but in terms of dependency on non-sustainable water, that makes up for $88 \%$ of the total demand. Until 2020, the expansion of CSP desalination will still be over-compensated by the annual growth of demand for freshwater. By 2025 global industrial CSP production capacities will finally have become large enough to cope with the growing demand, and the freshwater deficits can and must then be alleviated within a time span of 10-15 years. Fossil fuelled desalination will remain until 2050, as new plants built until 2025 will most probably be operated until the end of their economic life time which is about 20-25 years. 
Table 2: Main scenario indicators until 2050 for Saudi Arabia

\begin{tabular}{|l|l|c|c|c|c|c|c|}
\hline \multicolumn{1}{|c|}{ Saudi Arabia } & & $\mathbf{2 0 0 0}$ & $\mathbf{2 0 1 0}$ & $\mathbf{2 0 2 0}$ & $\mathbf{2 0 3 0}$ & $\mathbf{2 0 4 0}$ & $\mathbf{2 0 5 0}$ \\
\hline Population MP & $\mathrm{MP}$ & 21.5 & 27.7 & 34.0 & 40.1 & 45.3 & 49.5 \\
\hline Exploitable Water & $\mathrm{Bm}^{3} / \mathrm{y}$ & 2.4 & 2.4 & 2.4 & 2.4 & 2.4 & 2.4 \\
\hline Sustainable Water & $\mathrm{Bm}^{3} / \mathrm{y}$ & 2.49 & 2.75 & 3.19 & 3.80 & 4.57 & 5.49 \\
\hline Irrigation Efficiency & $\%$ & 0.43 & 0.46 & 0.49 & 0.51 & 0.54 & 0.57 \\
\hline Agricultural Use & $\mathrm{Bm}^{3} / \mathrm{y}$ & 19.1 & 23.1 & 26.7 & 29.8 & 32.0 & 33.3 \\
\hline Municipal Efficiency & $\%$ & 0.70 & 0.72 & 0.74 & 0.76 & 0.78 & 0.80 \\
\hline Municipal Use & $\mathrm{Bm}^{3} / \mathrm{y}$ & 1.8 & 2.49 & 3.22 & 4.02 & 4.81 & 5.57 \\
\hline Industrial Use & $\mathrm{Bm}^{3} / \mathrm{y}$ & 0.2 & 0.27 & 0.35 & 0.44 & 0.53 & 0.61 \\
\hline Total Demand & $\mathrm{Bm}^{3} / \mathrm{y}$ & 21.1 & 25.9 & 30.3 & 34.3 & 37.3 & 39.4 \\
\hline per capita Consumption & $\mathrm{m}^{3} / \mathrm{cap}^{\prime} \mathrm{y}$ & 982 & 933 & 891 & 855 & 824 & 797 \\
\hline Wastewater reused & $\mathrm{Bm}^{3} / \mathrm{y}$ & 0.091 & 0.400 & 0.800 & 1.400 & 2.200 & 3.100 \\
\hline Non-sustainable Water & $\mathrm{Bm}^{3} / \mathrm{y}$ & 18.6 & 22.9 & 23.7 & 6.9 & 4.4 & 1.6 \\
\hline CSP Desalination & $\mathrm{Bm}^{3} / \mathrm{y}$ & 0.00 & 0.18 & 3.39 & 23.6 & 28.31 & 32.36 \\
\hline Fossil Fuel Desalination & $\mathrm{Bm}^{3} / \mathrm{y}$ & 2.0 & 3.5 & 5.6 & 6.9 & 4.4 & 1.6 \\
\hline
\end{tabular}

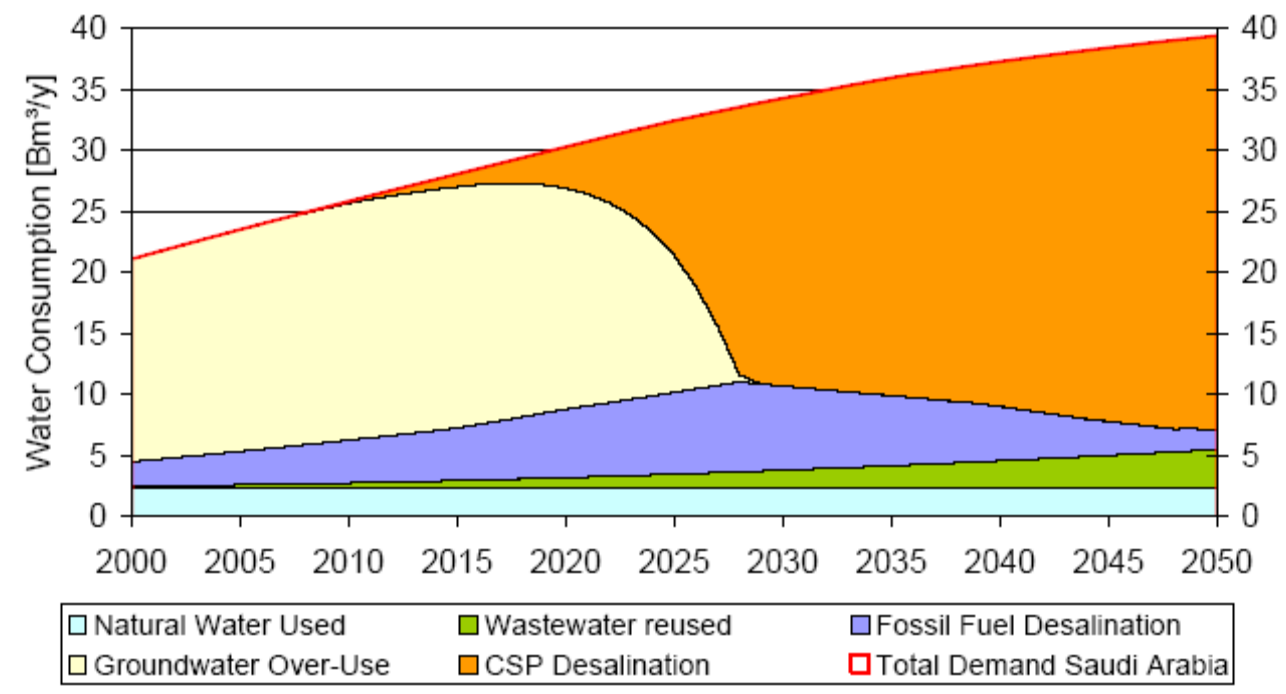

Fig. 6. Water supply scenario for the Saudi Arabia until 2050.

The share of agricultural water on the Saudi Arabia relatively high, with $89 \%$ today and $85 \%$ in 2050. Due to an only moderate share and growth of industrial and municipal water demand and a presently low efficiency of those sectors, the option of re-using waste water is rather limited. However, in the long term it will be an important factor of security and sustainability and will approximately supply the same amount of freshwater as the natural exploitable water resources. Saudi Arabia from the countries with the largest deficits on the Arabian Peninsula. However, all countries of the region suffer from severe water scarcity and a high dependency on non-sustainable sources. Therefore, the Saudi Arabia has the highest priority, and absolutely no alternative to immediately start market introduction and market expansion of CSP desalination systems. Having an important potential domestic market for CSP desalination, the necessary financial means due to its oil and gas exports, and with the initiatives already started in the some countries like United Arab Emirates, the Saudi Arabia has a very good chance to become a technology- and market leader for CSP desalination in the medium term future. In 2050, CSP desalination on the Saudi Arabia can make up for over $30 \mathrm{Bm}^{3} / \mathrm{y}$ of freshwater, which is almost the half of annual volume of the Nile river 
allocated to Egypt. In spite of this optimistic perspective and in spite of considerable future efficiency gains that were postulated in our scenario as described before, the per capita supply of water on the Saudi Arabia will have to be reduced from today about $933 \mathrm{~m}^{3} / \mathrm{cap} / \mathrm{y}$ to less than 797 $\mathrm{m}^{3} / \mathrm{cap} / \mathrm{y}$ in 2050 . This is due to a rapidly growing population from about 21.5 million in 2000 to over 48 million in 2050, which is one of the highest rates of population growth in the region of the Arabian Peninsula. With respect to sustainability, the above scenario leads to a desirable goal, which is characterized by:

- affordable cost of water from seawater desalination based on low energy cost from concentrating solar power,

- low environmental impact of power generation and seawater desalination, due to the use of renewable energy for desalination and due to the substitution of chemicals by renewable energy,

- low conflict potential due to water scarcity, and fair access to water for everybody due to the exploitation of a new, domestic source of water (seawater) and using a domestic energy source (solar energy) for desalination,

- economic stability due to low and stable cost of water for the economic development of arid regions,

- energy and water security.

\section{Initiatives to Benefit and Impediments to Growth of Solar Energy in Saudi Arabia}

Applications of solar energy in Saudi Arabia have been growing since 1960 [10]. Research activities commenced with small-scale university projects during 1969, and systematized major R\&D work for the development of solar energy technologies was started by the King Abdulaziz City for Science and Technology (KACST) in 1977 and is still continuing, recently announced on 24 January 2010 the launch of the National Initiative for Solar Water Desalination (NISWD) [1]. The solar-energy RD\&D activities throughout Saudi Arabia have confirmed that it has a multitude of practical uses in filed of water desalination. Saudi Arabia is already included in plans to bring considerable amount of solar power to Europe through the Desertec plan that aims to build a series of concentrating solar power plants in the Middle East (with several solar power stations on the Arabian peninsula) and North Africa with a connecting grid to Europe[7]. However, effective utilization of solar energy in Saudi Arabia has not yet made reasonable progress mainly due to several obstacles, some of which are listed as follows [11]:

i) The wide availability of oil, its superiority to solar energy as a source of energy and its relatively low cost

ii) The dust effect, which in some parts can reduce solar energy by $10-20 \%$.

iii) The availability of governmental subsidies for oil and electricity generation and non-availability of similar subsidies for solar energy programs. If such subsidies must continue then solar energy will require incentive programs.

\section{Conclusion}

The use of solar energy for desalination in Saudi Arabia appears nowadays as a reasonable, economically and technically mature option towards the emerging and stressing energy and water problems. 
The main conclusions are summarized:

1.The huge solar energy potential is already there and all that Saudi Arabia still needs is a necessary experience, and once these two combine it is very realistic to expect that Saudi Arabia will become major player in global solar power market.

2.The required solar technology should present small problem to Saudi Arabia considering its richness. Oil will likely remain the most exported good for Saudi Arabia for many more decades but solar energy could become dominant energy source in future.

3.Seawater desalination based on concentrating solar power offers affordable, sustainable and secure freshwater potentials that are large enough to cope with the growing deficits in Saudi Arabia.

4.The fact stressed the importance of the solar desalination as a national initiative since desalination was a strategic choice to ensure drinking water for the Saudi Arabia, which provides more than $18 \%$ of the world's production of desalinated water for a desalination plant producing $30,000 \mathrm{~m}^{3} / \mathrm{d}$.

5.Production of water by solar desalination is expected to reduce the cost of water production and electricity at a rate of up to $40 \%$ of the current cost.

6. Interaction between regional renewable research centers and local research centers and industries must be promoted to overcome any obstacles that hinder the effective utilization use of solar energy in Saudi Arabia and make it achievable in accordance with the huge solar energy potential.

\section{References}

1. Launching the first phase of the National Initiative for Water Desalination Using Solar Energy(NISWD),January 2010 KACST.

2. Desalination is the Solution to Water Shortages, redOrbit, May 2, 2008

3. Zhoua, Yuan, and Richard S.J. Tolb. "Evaluating the costs of desalination and water transport." (Working paper). Via a Hamburg University website. 2004-12-09. Retrieved on 2007-08-20.

4. MEDRC R\&D Report, Matching Renewable Energy with Desalination Plants, IT Power Ltd, 2001.

5. A.M. El-Nashar, " Predicting part load performance of small MED evaporators a simple simulation program and its experimental verification",2000, Desalination, Vol.130, pp. 217-234.

6. National Aeronautics and Space Administration (NASA),997, The Earth's Energy Budget, http://asd-www.larc.nasa.gov/SCOOL/energy_budget.html

7. Renewable Energy Articles, February 15, 2010, Solar energy in Saudi Arabia, Future prospect,http://renewableenergyarticles.blogspot.com/2010/02/solar-energy-in-saudi-arabiafuture.html.

8. Ali Al-Karaghouli, " renewable energy research a critical investment for the Arab region", 2007, WIPO/ IDB Regional Seminar for Arab Countries on Intellectual Property and Transfer of Technology Riyadh Saudi Arabia, pp. 4-6.

9. AQUA-CSP project, final report expected by December 2007, http://www.dlr.de/tt/aqua-csp

10. Huraib F. S, S. M. Hasnain and S. H. Alawaji "Lessons learned from solar energy projects in Saudi Arabia "Renewable Energy Vol. 9, No. 1-4 , 1996, pp. 1144-1147.

11. Alawaji S. H. "Evaluation of Solar Energy Research and its Applications in Saudi Arabia- 20 Years of Experience", 2001, Renewable and Sustainable Energy Reviews, Vol. 5, pp. 59-77. 


\section{Acronyms and abbreviations}

$\mathrm{CO}_{2} \quad$ Carbon dioxide

HD Humidification-dehumidification

SD Direct solar distillation

MD Membrane distillation

Desertec Clean power from deserts

MENA Middle East and North Africa

CSP Concentrating Solar Power

NISWD National Initiative for Solar Water Desalination

KACST KingAbdulazizCity for Science and Technology

RD\&D Research, Development and Demonstration

MCV Multi-vapor compression

TVC Thermal vapor compression

ED electrodialysis

RO Reverse osmosis 